\title{
The Clinical Approach to Stroke in Young Adults
}

\author{
Christopher A. Stack ${ }^{\bullet}$ John W. Cole ${ }^{2}$ \\ ${ }^{1}$ Stroke Program, University of Maryland Baltimore Washington Medical Center, MD, USA; \\ ${ }^{2}$ Department of Neurology, University of Maryland School of Medicine and Baltimore \\ Veterans Affairs Medical Center, MD, USA.
}

Author for correspondence: John W. Cole, 110 S. Paca St., 3rd Floor, Baltimore, MD

21201, USA. Email: jcole@som.umaryland.edu

Doi: https://doi.org/10.36255/exonpublications.stroke.adultstroke.2021

\begin{abstract}
Stroke in younger adults is less common than in older adults, with approximately $10-15 \%$ of all strokes occurring in adults aged 18 to 50 years of age. The pathogenesis of stroke in younger adults requires additional considerations for several less common risk factors and etiologies. As with any stroke patient, a thorough workup including evaluations of the brain, the blood vessels of the head and neck, the heart, and basic bloodwork must be performed. On the basis of these results, as well as case-specific clinical findings, family history, and other considerations, additional testing for genetic or hypercoagulable causes and specialized vascular and echocardiography can be performed. Overall, it is critical to identify the likely pathogeneses to prevent stroke recurrence. Regardless of pathogenesis, young stroke survivors with high rates of traditional risk factors must have these risk factors aggressively managed for long-term risk reduction. In this chapter, we focus on ischemic stroke in the young emphasizing a clinical evaluation framework, describing key considerations regarding etiology, treatment, and prevention that providers should contemplate in course of individualized patient care.
\end{abstract}

Keywords: acute stroke; monogenetic stroke disorders; prevent future strokes; risk factors; stroke in young adults

In: Stroke. Dehkharghani S (Editor). Exon Publications, Brisbane, Australia. ISBN: 978-0-6450017-6-1; Doi: https://doi.org/10.36255/exonpublications.stroke.2021

Copyright: The Authors.

License: This open access article is licenced under Creative Commons Attribution-NonCommercial 4.0 International (CC BY-NC 4.0) https://creativecommons.org/licenses/by-nc/4.0/ 


\section{INTRODUCTION}

Stroke remains a leading cause of mortality and morbidity, not only in the United States, but also worldwide (1-2). Stroke affects all ages from neonates to elderly patients alike. As one ages, stroke mechanisms, pathophysiology, etiologies, recovery, and prognosis change. A recent trend in the literature shows that young adult stroke patients, defined as patients aged 18 to 50 years old, are being hospitalized for strokes at an increasing rate (1, 3-9). During this same time interval, overall hospitalization rates for older patients has decreased (1, 3, 4, 7-9).

The importance of this observation has major impacts on individuals, families, society, healthcare costs/utilization and overall macroeconomics. Ischemic strokes exhibit high overall incidence, which affects its high mortality ranking nationally and worldwide. Strokes more often disable people than lead to death. The high disability drives these major familial, societal, and economic impacts. Young stroke patients are in their prime productive years in terms of work, child/family building, earnings, and societal contributions. Suddenly and unexpectedly succumbing to a highly disabling condition has long lasting and ubiquitous implications. Statistically, adults aged 18 to 50 years of age account for approximately $10-15 \%$ of all strokes (1, 3-9).

When clinically evaluating stroke patients there are 4 major questions to approach their care regardless of age.

- Question-1: Is this truly a stroke?

- Question-2: Is there anything that we can/should do now to treat the stroke?

- Question-3: What caused the stroke?

- Question-4: How do we best prevent future strokes from occurring?

This is the general clinical framework describing how to approach all stroke patients. In this chapter, we focus on ischemic stroke in the young using this general clinical framework as an outline, describing key considerations regarding etiology, treatment and prevention that providers should contemplate in course of individualized patient care.

\section{QUESTION 1: IS THIS TRULY A STROKE OR A MIMIC?}

The overall public awareness and knowledge about stroke signs and symptoms is slowly improving. National and local education focused on public education using mnemonics such as FAST (face, arm, speech, time) and BE FAST (balance, eyes, face, arm, speech time) are improving public stroke awareness. Such educational outreach efforts improve general public knowledge about strokes and work to compel patients to seek medical attention emergently when experiencing stroke symptoms.

Strokes occur suddenly. Hippocrates, the father of medicine, first recognized stroke over 2,400 years ago. At this time stroke was called apoplexy, which means "struck down by violence" in Greek. This phraseology was utilized because a person developed sudden paralysis and change in well-being. Strokes cause focal neurologic dysfunction resulting in a multitude of findings 
including, but not limited to, aphasia, visual field deficits, hemiparesis, hemi-body numbness and dysarthria. Stroke is a clinical diagnosis. The most important clinical differentiation is between hemorrhagic and ischemic stroke. Computed tomography (CT) of the brain is the only reliable rapidly implementable method to differentiate the two. Magnetic resonance imaging (MRI) is not required for clinical diagnosis of ischemic stroke. With that said, there is a higher preponderance of stroke mimics in young stroke patients. Common stroke mimics include brain tumors (e.g., gliomas, meningiomas, and adenomas), toxic or metabolic disorders (i.e., hypoglycemia, hypercalcemia, hyponatremia, uremia, hepatic encephalopathy, hyperthyroidism, thyroid storm), infectious disorders (e.g., meningoencephalitis), psychological disorders and migraines, seizures, and demyelization disorders. Although such etiologies physiologically differ from brain strokes, similarity of symptoms make the diagnosis difficult. Utilization of magnetic resonance imaging (MRI) of the brain is very helpful in differentiating true ischemic stroke from mimics. However, in the hyperacute phase of ischemic stroke diagnosis, treatment time is not a luxury, and timely medical decisions are imperative. Therefore, sometimes patients with stroke mimics will get hyperacute stroke therapy, including IV-tPA. We will discuss hyperacute treatment options below.

\section{QUESTION 2: IS THERE ANYTHING THAT WE CAN/SHOULD DO NOW TO TREAT THE ACUTE STROKE?}

Ischemic stroke treatment options are evolving rapidly. Our time windows and methods for intervention have exploded over the last few decades. As recently as the early 1990s, no hyperacute therapy for ischemic strokes existed. In the 1990s, intravenous (alteplase) tissue plasminogen activator (tPA) demonstrated reduced 3-month disability if administered within 3 hours of last known well (10). This window expanded in the mid-2000s to within 4.5 hours of last known well following results of the ECASS-III trial (11). In the mid-2010s, six landmark clinical trials showed the benefit of endovascular mechanical thrombectomy (EVMT) in patients with large vessel occlusion (LVO) presenting within 6 hours of last known well (12-17). More recently, the DAWN and DEFUSE-III trials expanded the EVMT treatment window up to 24 hours from last known well $(18,19)$. Now, increasing evidence shows imaging modalities like MRI/P and CTP may help guide utilization of thrombolytics up to 24 hours from last known well (20-23).

Despite the higher incidence of stroke mimics in young patients as discussed above, one should not let that dissuade clinicians from implementing hyperacute acute stroke therapy strategies if such patients are within guidelines for use. For thrombolytics, intracerebral hemorrhage risk in patients who are having a stroke mimic are very low, $0.4 \%$ (24). Unless one is absolutely certain that the patient is having a stroke mimic, the recommendations are to 'err' to proceed with thrombolytic therapy. Despite a non-contrast CT brain being the only obligatory imaging test in the acute ischemic stroke diagnosis, advanced stroke diagnostic imaging modalities such CT angiogram (CTA), CT perfusion (CTP), MRI, MRA can be used to help guide precision stroke care. 


\section{Other acute stroke care considerations}

Young patients who demonstrate large hemispheric ischemic strokes are at high risk of developing malignant cerebral edema. Data indicates decompressive hemicraniectomy (DHC) for middle cerebral artery (MCA) infarcts within 48 hours of stroke onset reduces poor outcome and case fatality in young stroke patients (25). Some data show glyburide may be a future treatment option for malignant cerebral edema (26). The CHARM study is an ongoing phase III clinical trial exploring the efficacy of glyburide in these patients (27). Posterior fossa ischemic strokes require close monitoring because of the risk of malignant cerebellar edema leading to rapid clinical deterioration. Unchecked malignant cerebellar edema may lead to life-threatening acute obstructive hydrocephalus as well as brainstem damage. In such situations, treatment is an emergent surgical posterior fossa decompression procedure.

\section{QUESTION 3: WHAT CAUSED THE STROKE?}

Broadly speaking, all ischemic strokes are due to problem(s) originating with the heart, the blood vessels or the blood. Patients clinically diagnosed with an ischemic stroke require a thorough evaluation for the cause of their stroke. This cannot be emphasized enough; clinicians must ask why is this patient having a stroke? The etiology dictates the prognosis, recurrence risk and optimal secondary stroke prevention strategy. The framework used is a 'heart-to-head' or (head-to-heart) approach. This includes detailed history, physical exam, and various diagnostic tests.

\section{Head/Brain}

The clinical presentation and exam give clues as to the etiology by virtue of the clinical localization (i.e., part(s) of brain impacted by stroke). Cortical signs such as aphasia, gaze deviation, neglect, extinction, constructional dyspraxia, astereognosis, agraphesthesia and visual field cut(s) suggest an embolic source. Conversely, lacunar syndromes such as pure motor hemiparesis, pure sensory hemi-body numbness, and clumsy hand-dysarthria syndrome suggest small vessel disease etiology.

An MRI of brain is not a requirement for the diagnosis of stroke; however, MRI provides important diagnostic information especially in young stroke patients. MRI brain can help differentiate a stroke from a stroke mimic such as multiple sclerosis.

The pattern of stroke seen on MRI certainly helps with the etiologic considerations. Cortical based infarcts on MRI in multiple vascular territories or bilateral hemispheric involvement suggest a proximal vasculature embolic source such as a cardioembolic stroke. Other patterns can be highly suggestive of rare stroke causes such as Cerebral Autosomal Dominant Subcortical Infarcts and Leukoencephaly (CADASIL). In CADASIL, MRI shows damage to the anterior temporal poles and extreme capsule. These MRI patterns and etiologic clues focus clinicians' diagnostic efforts regarding patient workups and testing. For example, 


\section{TABLE 1 Treatment interventions among select young-onset stroke patients}

\begin{tabular}{|c|c|}
\hline Condition & Therapeutic Considerations \\
\hline Sickle Cell disease & $\begin{array}{l}\text { - Exchange transfusion }(172,173) \text { age } 2-16 \text {. } \\
\text { ** Indications: } \\
\text { 1. Transcranial doppler MCA velocity } \geq 200 \mathrm{~cm} / \mathrm{s} \\
\text { 2. Ages } 2-16 \text { (not well established outside this age range) } \\
\text { 3. Primary stroke prevention }\end{array}$ \\
\hline Fabry Disease & $\begin{array}{l}\text { - Recombinant alpha galactosidase } \\
\text { ** Efficacy in stroke reduction is unclear (174). }\end{array}$ \\
\hline $\begin{array}{l}\text { Moya-Moya Disease and } \\
\text { Syndrome }\end{array}$ & $\begin{array}{l}\text { In refractory cases various revascularization procedures can be considered } \\
\text { Adults: } \\
\text { 1. External carotid artery to middle cerebral artery (ECA-MCA) } \\
\text { anastomoses } \\
\text { 2. Superficial temporal artery to middle cerebral artery bypass } \\
\text { (STA-MCA) } \\
\text { Children (vessels too small for direct anastomosis) } \\
\text { 1. Encephalomyosynangiosis (EMS) } \\
\text { 2. Encephaloduroarteriosynagniosis (EDAS) } \\
\text { 3. Encephaloduroarteriomyosynagiosis (EDAMS) }\end{array}$ \\
\hline $\begin{array}{l}\text { Primary and secondary } \\
\text { CNS vasculitis }\end{array}$ & $\begin{array}{l}\text { Steroids } \\
\text { Intravenous immunoglobulin } \\
\text { Plasma exchange therapy } \\
\text { Long Term: Steroid-sparring immunosuppressants }\end{array}$ \\
\hline
\end{tabular}

patients with multifocal cortical strokes should undergo thorough structural (transthoracic echocardiogram [TTE] and transesophageal echocardiogram [TEE]) and electrical cardiac analysis for cardioembolic causes. A bubble-study evaluation for a patent foramen ovale (PFO) should be performed, and if a PFO is identified, paradoxical emboli sources such as a deep vein thrombosis (DVT) should be considered.

\section{Vertex to arch evaluation}

A skull vertex to aortic arch evaluation refers to an examination of the cerebral vasculature from the skull vertex down through the neck to include the aortic arch. This evaluation is critical to help determine an etiology for an ischemic stroke. An appropriate evaluation assesses the entire arterial vasculature of the upper-chest, neck and head. Arteriopathies cause strokes via "downstream" thromboembolic damage (i.e., carotid atheroembolism) or in-situ occlusive events. Arteriopathies are especially prevalent and important etiologic considerations in young stroke patients.

The initial vertex to arch evaluation should be non-invasive. CTA or MRA (ideally with gadolinium) of the head and neck adequately evaluate the cerebrovascular tree. These modalities increase the diagnostic information gathered compared to the more limited carotid ultrasonography, although both grayscale and Doppler 
US can be used for evaluation of extracranial segments of the carotid artery, with the complex of these two methods being referred to as duplex ultrasound (DUS). These techniques allow for assessment of vessel morphology and assessment of vascular wall atherosclerotic changes and can differentiate between calcified and noncalcified plaque. Such findings are used for subsequent assessment of risk stratification, although in younger patients severe atherosclerosis is less commonly seen.

In young patients, clinicians must be particularly mindful of the venous vasculature. Brain CT venogram (CTV) and MR venogram (MRV) do not need to be part of the standard vertex to arch evaluation, however, in certain clinical situations further exploration with CTV or MRV is warranted (described below).

We will now discuss some of the stroke etiologies that can be determined or highly suggested based upon the results of the vertex to arch evaluation.

\section{Large artery atherosclerosis}

Large artery atherosclerosis (LAA) is more common in older adults and less common in young stroke patients accounting for less than 10\% of young-onset cases (28). Despite the lower incidence, it is particularly important to discover because LAA has a high mortality risk. The mortality risk in young stroke patients portends a $60 \%$ mortality over 17 years (29). LAA includes both intracranial and extracranial disease. Intracranial disease includes symptomatic atherosclerotic stenosis of intracranial internal carotid arteries, the circle of Willis, and vessels originating off the circle of Willis including the bilateral MCA, ACA and PCA arteries. Extracranial disease can affect any vessel between skull base to the heart, including the extracranial portions of the internal-, common-carotid and vertebral arteries, including their origins on the brachiocephalic trunk, innominate and subclavian arteries and the proximal aorta.

Given the wide age range between $18-50$ years, young stroke patients can be quite heterogeneous. For instance, a 45-year-old smoker has a very different risk profile than a 20 -year-old athlete. In fact, LAA increases after age 35 in correlation with an increase in more traditional vascular risk factors (30-32). Well-established precursors for atherosclerotic disease include smoking, hypertension, diabetes, and hyperlipidemia $(9,33,34)$. Therefore, it is important to screen and mitigate these risk factors in the LAA patient population in order to lower recurrent stroke risk and reduce future risk of cardiovascular death.

\section{Cervicocerebral arterial dissection}

Cervicocerebral arterial dissection accounts for 10-25\% of ischemic strokes in the young (33-36). Dissection typically affects extracranial vessels, with the vertebral arteries having the greatest incidence $(4,31,32,37-39)$. Dissections are associated with different forms of trauma, both minor and severe. These include traumas such as coughing, vomiting, retching, sudden high velocity acceleration and/ or deceleration head movements (e.g., chiropractic manipulation, sexual intercourse, motor vehicle collision, contact sports). Notably, most dissections are actually spontaneous without clear provocation (40). Predisposing factors are controversial, but studies demonstrate migraine, recent infection, hypertension, 
smoking, pregnancy, oral conceptive use, hyperhomocysteminemia, and the autumn season as predisposing factors (41-49). Conversely, some data suggest hypercholesterolemia and obesity are protective (50-52).

The preferred initial screening modality to evaluate for dissection is CTA of head and neck. If the index of suspicion remains high despite negative initial imaging, one can consider using MRA T1-fat saturation imaging technique. The best timing for this study is 3-7 days after the stroke/dissection event demonstrating a crescentic hyperintensity in the vessel wall. At this time the dissections' vessel wall hematoma becomes bright on $\mathrm{Tl}$ with the development of intracellular methemoglobin (53).

\section{Fibromuscular dysplasia (FMD)}

FMD affects cervicocerebral arteries and renal arteries. Young women with refractory hypertension and strokes are the most commonly affected demographic, but it is important to note that FMD does not exclusively affect young women (54-56). Conventional cerebral angiography as well as the coronal and sagittal views on CTA/MRA show a 'string of beads' or a 'stack of coins' pattern that are considered pathognomonic for FMD. These imaging findings and clinical factors lead to the diagnosis of FMD.

\section{Moya-Moya}

Moya-Moya accounts for 6-15\% of vasculopathies not due to LAA (28). The name, Moya-Moya, means "puff of smoke" which is the appearance seen on the angiogram. Conventional cerebral angiography is the diagnostic test of choice. This appearance is a result of bilateral intracranial carotid artery severe stenosis or occlusion with associated dilatation of the lenticulostriate arteries. However, clues on MRI brain show tortuous flow voids (in affected lenticulostriates, thalamoperforators, dural arteries) and multiple susceptibility weighted imaging (SWI) microbleeds.

Moya-Moya disease is a genetic disease while Moya-moya syndrome is secondary to other causes. Conditions associated with Moya-Moya syndrome include sickle cell disease, neurofibromatosis type 1, tuberous sclerosis, cranial radiation, antiphospholipid antibody syndrome, Marfan syndrome, Ehler-Danlos syndrome, polycythemia vera and Down syndrome (57-64).

\section{Reversible cerebral vasoconstriction syndrome}

Reversible cerebral vasoconstriction syndrome (RCVS) often presents with recurrent thunderclap headaches. Patients will often have exposure to vasoactive substances (e.g., cocaine and serotonergic medications). This can be a cause of stroke like symptoms without stroke, but can also lead to strokes. Angiography demonstrates vasoconstriction that resolves in subsequent imaging. The condition is more commonly diagnosed in women between the ages of 20 to 50, and may be associated with the hormonal changes that happen in the body immediately after giving birth (postpartum) or changing birth control pills. A history of migraine is also common among patients with RCVS. 


\section{Inflammatory vasculopathies}

Inflammatory vasculopathies are conditions for which the walls of blood vessel become inflamed. This leads to ischemic strokes via in situ thrombosis or vasoconstriction. In young stroke patients, inflammatory vasculopathies are most often infectious. These infections include syphilis, tuberculosis, human immunodeficiency virus (HIV) and varicella zoster virus (VZV), as well as bacterial and fungal infections. Infectious vasculitis is a form of secondary central nervous system (CNS) vasculitis. Other examples of secondary CNS vasculitis are systemic inflammatory condition such as lupus, Behcet's syndrome, granulomatosis with polyangiitis, microscopic polyangiitis, rheumatoid arthritis and sarcoidosis. Primary CNS vasculitis (PACNS) occurs when the vasculitis affects the brain and/ or spinal cord vasculature without any evidence of an underlying systemic inflammatory disorder.

Susac syndrome is a unique condition that falls under the umbrella of inflammatory vasculopathies. More specifically, it is a rare autoimmune-mediated endotheliopathy, characterized by impaired brain function (encephalopathy), branch retinal artery occlusion and inner ear disease (hearing loss). Patients on MRI have classic "snowball lesions" affecting the corpus callosum (65).

Cerebral vasculitis is a challenging condition to diagnose. It is largely a clinical diagnosis, but there are clinical findings that support the diagnosis. Infarcts are often multifocal, but imaging findings on MRI are variable. Non-invasive angiography should be used as the initial screening modality, but small vessel vasculitic changes may not been seen on CTA and MRA. When the index of suspicion is high enough, one should perform conventional cerebral angiography to obtain better resolution of the small and large arteries.

The invention of vessel wall imaging occurred in recent years and can be employed in the setting of suspected vasculitis. Although, the clinical utility of this new technology is not yet fully established. Interpretation of this new technology requires some caution. However, this methodology brings the medical community closer to understanding vasculitic-related strokes. Black-blood MRI/A, also known as spatial pre-saturation MRI, is the preeminent example of cerebral vessel wall imaging. It noninvasively visualizes the vessel wall for thickening and enhancement patterns that occur in vasculitis as opposed to intracranial atherosclerosis (ICAS). Black-blood MRI/A suppresses (rendering it "black") the signal from flowing blood rather than enhancing it as in conventional bright-blood MRA techniques. In other words, black-blood MRA converts the lumen into a low signal and displays the vessel walls with increased image clarity. Therefore, black-blood MRA is able to determine the presence and extent of stenosis, in addition to accurately identifying wall inflammation associated with vasculitis from stenotic atherosclerotic lesions.

Lumbar puncture (LP) is another recommended diagnostic testing in the evaluation of CNS vasculitis. The main purpose of the LP is to evaluate for an infectious vasculitis. The CSF profile for non-infectious vasculitis is non-specific. CSF studies suggested include cell count, cell differential, protein, glucose, gram stain and culture, fungal stain and culture, HSV PCR, VZV PCR, cytomegalovirus (CMV) PCR, Venereal Disease Research Laboratory (VDRL), flow cytometry, cytology and tuberculosis PCR. In rare instances, one can consider performing a leptomeningeal biopsy to evaluate for evidence of CNS vasculitis. This is usually 
reserved for cases where a diagnosis is not established and there is a precipitous clinical decompensation.

\section{Cerebral venous sinus thrombosis}

Cerebral venous sinus thrombosis (CVST) is a relatively rare cause of stroke accounting for approximately $0.5-1 \%$ of strokes $(66,67)$. If patients have infarcts or hemorrhages that do not fit classic arterial vascular territory patterns, one should image the venous anatomy to evaluate for CVST. Younger women are a higher risk group for CVST. The ISCVT clinical trial demonstrated a median age of diagnosis of 37 years old with $74 \%$ of patients being female (68). Another study showed women aged 31-50 years old carry a CVST incidence of 2.78 per 100,000 person-years $(69,70)$. Other factors that contribute to high CVST include women of childbearing age, estrogen containing oral contraceptive use and current smoking. CVST often has delayed diagnosis. Clinicians fail to recognize CVST because of its variable presentation. CVST patients most often present with headache (90\%) and seizure (40\%) (68). The ISCVT trial demonstrated 7 days until diagnosis and 4 days from symptom-onset until admission $(68,71,72)$.

The major mechanisms of neurologic dysfunction associated with CVST are increased intracranial pressure (ICP) and infarction, although seizures can also occur. Poor venous outflow leads increased cerebral venous resistance and decreased CSF drainage, which results in increased ICP (73). Symptoms of increased ICP include headache, diplopia (i.e., abducens palsy) and papilledema. Venous infarction is the other mechanism of injury, with stroke mechanisms including ischemia, hemorrhage or hypoperfusion.

\section{Cardiac sources of stroke}

Cardioembolic strokes represent one of the highest of identified stroke etiologies in young adult patients, accounting for $\sim 20 \%$ of causes $(74,75)$. In contrast to older patients, atrial fibrillation and other dysrhythmias are rare (76). All patients should undergo standard 12-lead EKG and inpatient telemetry monitoring regardless of age. Clinicians should consider implantable loop recorders in young patients with embolic stroke of undetermined source (ESUS) when the clinical concern for atrial fibrillation is high. Implantable loop recorders yielded 25.5 detection rate in ESUS patients, but the utility is much higher in older patients (74).

Structural cardiac lesions are more concerning in young patients. These include left atrial thrombus, left ventricular thrombus, infectious endocarditis, non-infectious (marantic) endocarditis, cardiac tumors (i.e., myxomas), valvular disease, cardiomyopathy and PFO. As mentioned, transthoracic echocardiogram (TTE) with bubble is a high yield test for PFO. Furthermore, transesophageal echocardiogram (TEE) is an important diagnostic test in young patients with embolic appearing strokes if the TTE is unrevealing. In older patients, TEE is rarely a beneficial test. In young patients, TEE alters management $16.7 \%$ of the time (77). Additional etiologies discovered by TEE include endocarditis, aortic arch atheroma, intracardiac thrombus, pulmonary arteriovenous malformation, 
intracardiac tumors and valvular masses. PFO is the most common "intervenable" etiology discovered on TEE.

PFO and stroke has been a topic of controversy over the past several decades. In recent years, large clinical trials demonstrated a benefit of closing PFOs in select younger stroke patients. PFOs occur in $25 \%$ of non-stroke patients, but $50 \%$ in young stroke patients $(28,30)$. Despite this increased incidence, early clinical trials did not demonstrate benefit of PFO closure (78-80). However, three more recent trials, CLOSE, REDUCE, RESPECT-part 2 demonstrated decreased stroke events following PFO closure (81-83). Given how selective the inclusion criteria were in these studies, PFO closure is recommended in only select patients. The recommended inclusion criteria are: (i) embolic stroke of undetermined source (ESUS); (ii) TEE that ruled out endocarditis or alternative etiology; and (iii) TEE demonstrates atrial septal aneurysm [septum primum excursion $>10 \mathrm{~mm}$ ] and/or large intracardiac shunt [>=30 microbubbles in left atrium within 3 cardiac cycles using agitated saline]. Patients satisfying these criteria should be aware of the risk of peri-procedural and post-procedural atrial fibrillation of 4.6-6.6\%. If the patient agrees with PFO closure, clinicians should refer the patient to an experienced interventional cardiologist with experience in PFO closure. These patients should remain on long-term antiplatelet therapy for secondary stroke prevention even after PFO closure.

Young patients in the Baltimore-Washington Young Stroke Study showed that the most common cardiac causes in young stroke patients was bacterial endocarditis (84). When a young stroke patient has an embolic appearing stroke, clinicians should strongly consider ordering erythrocyte sedimentation rate (ESR), C-reactive protein (CRP), blood cultures and TEE, in addition to the standard TTE. Abdominal $\mathrm{CT}$ can evaluate for the presence of kidney or splenic embolic infarcts. A diagnosis of non-infectious endocarditis (murantic) requires thorough history, exam, and diagnostic evaluation for underlying rheumatologic conditions.

Cardiomyopathies indicate a 10-100-fold increased stroke risk in young adults (85-88). TTE with bubble, TEE, and cardiac MRI can be used to identify and evaluate for cardiomyopathies.

\section{Evaluating for traditional vascular risk factors}

Traditional vascular risk factors include hypertension, hyperlipidemia, diabetes, and smoking. Regardless of age, the presence of these factors is associated with higher risks of recurrent stroke (89). In young patients, the most prevalent factors are hyperlipidemia (60\%), smoking (44\%), and hypertension (39\%) (31, 32). All stroke patients require routine measurements of blood pressure, as well as hemoglobin Alc and a lipid profile (especially LDL cholesterol), both of which are standard laboratory tests (68). Healthcare teams must aggressively counsel patients to quit smoking, including their families to prevent future secondary exposure.

\section{Recreational drugs and alcohol}

All young stroke patients should undergo urine toxicology testing on admission. Recreational drugs account for up to $12 \%$ of young strokes (90). Additionally, one 
should take a careful history with regard to alcohol use because overuse of alcohol is an independent risk factor in young stroke patients (91). The potential mechanisms include cardiac arrhythmias, traumatic injuries leading to dissection of cervicocerebral vessels and effects on clotting/coagulation (92).

One should ask about the drugs of abuse, the method and frequency of use. As discussed above, infectious endocarditis is a one of the most common causes of stroke in young. The risk is much higher in intravenous drug abuse (IVDA). Heroin is commonly an injected drug and thus associated with infectious endocarditis. Smoking heroin, called "chasing the dragon," can induce a toxic leukoencephalopathy, which can mimic stroke like symptoms (93).

Cocaine increases the risk of stroke 6-fold within 24 hours of use. Inhalation of crack-cocaine portends the highest risk (94). Frequent cocaine use, defined as cocaine use more than once/week, demonstrated 2-fold higher risk of ischemic stroke (94).

Although marijuana is becoming increasingly legal in the United States of America, one still needs to screen for its use whether recreationally or medicinally. Many studies have evaluated the association between stroke and marijuana use yielding mixed results. More recent studies demonstrate higher ischemic stroke rates in young adult marijuana users (95). Potentially daily uses portend the greatest risk. Clinicians should specifically ask about synthetic marijuana especially in patients who undergo routine drug testing (military personnel, athletes, parolees). Amphetamines and designer drugs are additional considerations.

\section{Special considerations for stroke in young women}

Migraine is associated with increased stroke risk. Migraine is not a definitive cause of stroke, but there are multiple positive association studies. The risk relationship is specifically with migraine with aura. In women, migraine with aura doubles stroke risk (96). In fact, this stroke risk further increases with smoking and oral contraceptive use (OCP) (97-99). A meta-analysis of patients aged 30-50 showed an adjusted odds ratio of 2.3 for migraine with aura (100). No association exists between stroke and migraine without aura. Notably, these data were adjusted for several confounders including hypertension, smoking, estrogen containing oral contraceptives, cardiac disease and history of stroke. A dangerous tetrad, portending 30-fold increased stroke risk, is young women who are migraineurs with aura, smokers and use oral contraceptives (101). In such patients, clinicians must encourage patients to quit smoking and consider alternative contraceptive methods.

Combined oral contraceptives (estrogen and progesterone containing OCPs) demonstrated a 1.7 to 6 time relative risk of stroke compared to women not on OCPs (102). This risk increased with higher doses of estrogen and it was demonstrated to show a 2 -fold increase for women who were taking estrogen dosages $>=50 \mathrm{mcg}(102)$.

Young women have specific hormonal factors that create a prothrombotic state. Support of this theory includes the observation that the incidence of cerebral venous sinus thrombosis (CVST) among elderly and children is sex-independent $(103,104)$. Additionally, CVST is associated with ovarian hyperstimulation syndrome (105). CVST in OCP users show 5.6 to 15.9-fold increased stroke risk 
in studies $(106,107)$. OCP use demonstrated a synergistic effect with hereditary thrombophilias as demonstrated by odds ratio of 149.3 (108, 109).

Pregnancy is a rare, but observed, risk factor for stroke. A recent study suggests it occurs in less than 20 per 100,000 pregnancies (110). This risk is highest in the $3^{\text {rd }}$ trimester and through the first 12 weeks post-partum (111). This postpartum time-period correlates with an increased hypercoagulable state. The pathophysiologic mechanisms are many, but clinicians should be aware of eclampsia, cardiomyopathy in pregnancy (and peripartum), amniotic fluid embolism, CVST and RCVS $(112,113)$.

\section{Hypercoagulable states}

Intuitively, one would think that hypercoagulable states would be a major contributor to early-onset stroke. However, the science and data, do not demonstrate a strong link between hypercoagulable states and arterial ischemic stroke. Results vary in many studies regarding the incidence of various genetic thrombophilias. In general, one should not routinely screen young stroke patients for inherited thrombophilias. These include the factor V Leiden mutation, prothrombin gene mutation, protein $\mathrm{C}$ deficiency, protein $\mathrm{S}$ deficiency, and antithrombin deficiency. These thrombophilias show a clear association with venous thrombosis, but not arterial ischemic stroke (114). Data suggest that strokes in young patients with established inherited thrombophilias in the presence of traditional vascular risk factors exhibit a "gene-dose effect" that may increase risk when combined with smoking, hypertension and OCP use $(115,116)$. However, sending off a genetic panel typically does not alter management and thus is not recommended.

One exception to the above discussion is antiphospholipid antibody syndrome (APS). There have been mixed results, but a link between APS and arterial ischemic stroke has been more consistently demonstrated than other thrombophilia. APS incidence has been shown to be $~ 5$ cases/100,000 persons per year and associated with recurrent stroke in young adults $(28,117)$. However, a recent large meta-analysis data evaluating APS and its association with recurrent ischemic strokes did not yield a positive result (118). The major detraction from this study was the inconsistent definition of APS. Therefore, APS syndrome in young stroke patients should be considered part of routine screening. Patients with confirmed APS require therapeutic anticoagulation with warfarin for secondary stroke prevention. Studies of direct oral anticoagulants (DOACs) in APS are lacking.

Notably, there are rare instances to send an extended diagnostic panel assessing for genetic thrombophilias in young stroke patients. One instance is a stroke that results from a paradoxical embolus via a PFO, or where there is a history of prior unprovoked venous thromboembolic events, or an unprovoked deep venous thrombosis is identified. Identifying such a thrombophilia is important because it will potentially alter the secondary prevention strategy from antithrombotic therapy to anticoagulation therapy, particularly if the PFO is not closed. In such settings, both cardiology and hematology consultations are warranted.

Clinicians should test for genetic thrombophilias in CVST. More data exists showing a link between genetic thrombophilias and venous infarcts with $22 \%$ of patients in the ISCVT trial having a genetic hypercoagulable state (119). Specifically recommended tests include evaluations for G20210A prothrombin mutation, Factor V Leiden, APS labs (cardiolipin antibodies, beta-2-glycoprotein and lupus 
anticoagulant), protein $\mathrm{C}$ deficiency, protein $\mathrm{S}$ deficiency and antithrombin III deficiency, as listed in decreasing order of strength of association (68, 109, 120-124).

\section{Malignancy}

Cancer exhibits an increased risk for stroke in young patients (125). Theorized mechanisms include an inherent hypercoagulable state, toxic effects of chemotherapy (i.e., cardiomyopathy), cerebrovascular effects of radiation, direct effects of solid tumors, and intravascular effects of lymphoma. One study showed $7 \%$ of young stroke patients had an underlying cancer, with 4.1\% diagnosed during their index stroke event or thereafter (126). This association not only includes patients with active cancer, but also stroke survivors who have an estimated 2-fold risk of stroke, with primary CNS tumors, head/neck tumors and leukemias portending the highest risk (126).

Patients with CVST showed $7.4 \%$ incidence of cancer, especially primary CNS tumors, metastatic solid tumors and hematologic malignancies (68, 119). Suggested mechanisms are inherent hypercoagulability, venous sinus tumor invasion or compression, a pro-inflammatory state, chemotherapy, and hormone therapy (i.e., tamoxifen) (127-130).

\section{INFECTIONS}

In previous sections we discussed infectious stroke mechanisms including infectious vasculopathy and endocarditis, respectively. In this section, we discuss chronic and recent infections as a stroke risk factor as opposed to the direct mechanism of the stroke. The most common systemic infection associated with acute ischemic stroke are respiratory infections (131). It is good clinical practice to ask a detailed history regarding recent infections. Infections within four weeks of index stroke occurred in $10.7 \%$ of young stroke patients (132). Special populations to consider an infectious contribution include prisoners, immunosuppressed individuals, and foreign travelers. Tuberculosis, HIV, neurocystericercosis, Chagas disease and syphilis are associated with stroke in young (131-134).

Chronic infections also increase stroke risk. One theory is that chronic inflammation causes a pro-thrombotic state. One such example is chronic periodontiis (131-133). It is important to counsel stroke patients about proper oral hygiene and routine dental care.

At the time of writing this chapter, we are amidst the global coronavirus 19 (COVID-19) pandemic. The data and science are constantly evolving regarding stroke and COVID-19 infection. As the data increases, there appears to be a link between COVID-19 and stroke. Recent studies shed light on the characteristics of COVID-associated stroke. In the early phases of the disease in New York City, younger patients had large vessel occlusions in association with COVID-19 infection (135). In larger studies, there remains a predisposition to large vessel occlusions $(136,137)$. Therefore, it is not surprising that COVID-19-associated strokes have higher National Institute of Health Stroke Scale (NIHSS) scores signifying more severe strokes $(138,139)$. COVID-19 strokes occur more often in the 
hospital (140). Imaging shows multifocal strokes and silent cerebral infarcts (141). COVID-19 patients demonstrate worse overall outcomes. Even more concerning, at the peak of the pandemic, patients with minor strokes avoided hospitals and medical attention (142). Proposed pathophysiology and stroke mechanisms for COVID-19-associated strokes include hyperinflammation, hypercoagulable state, cardiac injury, endothelial injury, and direct CNS invasion. The medical community is still gathering data and these studies are subject to sampling bias. One should interpret the early data with some caution and diligently track the association between COVID-19 and stroke going forward.

CVST is also associated with infections. Infections were present in $8.2 \%$ of patients in the ISCVT trial (68). Locations that were particularly high risk included ear, sinus, mouth, face, and neck with cavernous sinus thrombosis being due to face/nasal sinus infections. Lemierre's syndrome is thrombosis of the internal jugular vein due to oropharyngeal infection. In rare cases, inflammation associated with Lemierre's syndrome can envelop the nearby internal carotid artery (ICA) leading to a focal vasculitis that can go on to cause ipsilateral cerebral embolic infarcts.

\section{Monogenetic stroke disorders}

Monogenetic stroke disorders are rare Mendelian disorders that arise from a single gene defect and are estimated to account for less than 1\% of young strokes (143). There are data to suggest this may be an underestimate due to lack of recognition to screen for monogenetic causes. Some studies estimate the incidence in young stroke patients could be up to $7 \%(144,145)$. To be clear, these are not "stroke genes;" rather, they are genetic conditions in which stroke is a presenting feature. Some of the conditions exhibit stroke as a rare manifestation and other as more prominent feature. Appropriately diagnosing these genetic stroke disorders can have implications on prognosis, treatment, and family planning. It also alerts clinicians to the likelihood of other organ systems being involved or than can become involved. For example, Fabry disease that presents as stroke should signal the clinician to educate the patient about the high likelihood of renal failure in the future.

In young patients with unexplained strokes, the patterns on MRI, family history, associated alternative organ dysfunction can signal clinicians to delve further and consider these rarer causes of stroke. Notably, having traditional vascular risk factors should not preclude one from considering monogenetic causes of strokes. There are certainly features on the head-to-heart diagnostic workup that can strongly suggest a diagnosis. For example, CADASIL pathognomically shows white matter hyperintensities in the bilateral extreme capsules and anterior temporal poles. The latter of which is termed the O'Sullivan sign (146). As mentioned previously, vascular imaging that shows a "stack of coins" appearance in the carotids on CTA/MRA/conventional angiography strongly suggests FMD as the stroke etiology.

When providers have a clinical suspicion for a monogenetic cause of a stroke, a very detailed family history including a family pedigree should be performed. Family history of stroke at an early age is one of the strongest indicators of an underlying monogenetic stroke disorder. Beyond stroke, deficits in other organ systems should be explicitly queried in at least all first-degree relatives, but 
extended family pedigrees should be evaluated if that data is available. This will provide insight on possible transmission pattern (e.g., dominant, recessive, maternal). Documenting the age-of-onset of any strokes, various disease processes, and age at death should be included. If a concerning pattern emerges, a formal genetics consultation should be requested.

There are many stroke-associated monogenetic disorders (147-149) and an in-depth discussion of each of these is beyond the scope of this chapter.

\section{HOW DO WE BEST PREVENT FUTURE STROKES FROM OCCURRING?}

By definition, the optimal secondary stroke prevention strategy aims to reduce stroke recurrence. This is especially important considering the 9.4\% 5-year recurrence risk in young patients (150). The risk factors associated with this recurrence risk include traditional vascular risk factors, a large artery atherosclerotic disease primary etiology, diabetes, prior TIAs, and heart failure (39). This recurrence rate highlights the importance of education beginning during the hospitalization of the index event. Medical, lifestyle, and in certain circumstances, surgical/procedural interventions are indicated. Every patient is a unique case. Each case requires an individualized plan considering their specific needs. Although, many tenets of stroke secondary prevention are ubiquitous among stroke patients.

The stroke etiology strongly dictates whether a stroke patient needs antithrombotic or anticoagulant therapy. In most circumstances, patients will be on antithrombotic therapy. In recent years, the utilization and data supporting the use of dual antiplatelet therapy (DAPT) has changed the practice patterns of most vascular neurologists and stroke care providers. There are three main indications for DAPT: (i) high risk TIA; (ii) minor ischemic stroke (NIHSS <4); and (iii) strokes resulting from symptomatic intracranial atherosclerosis. The first two indications generally requiring only 21 days of dual antiplatelet therapy to lower the recurrent stroke risk $(151,152)$. The treatment regimen includes aspirin $81 \mathrm{mg}$ daily plus clopidogrel $300 \mathrm{mg}$ or $600 \mathrm{mg}$ loading doses followed by clopidogrel $75 \mathrm{mg}$ daily for 20 subsequent days. After 21 days, the patients continue monotherapy (single antiplatelet) at the discretion of the care provider (either aspirin or clopidogrel monotherapy). In patients with symptomatic intracranial atherosclerosis the duration of DAPT is extended to 90 days given the higher risk profile and results from the SAMMPRIS clinical trial (153).

Anticoagulation is the treatment of choice in specific stroke etiologies. The highest level of evidence supports anticoagulants warfarin, apixaban, rivaroxaban, dabigatran to treat cardioembolic strokes related to atrial fibrillation (154-157). In addition to atrial fibrillation strokes, another strong indication includes strokes related to CVST. Patients with confirmed CVST require immediate treatment with either unfractionated or low molecular weight heparin followed by warfarin for 3-6 months (71). Strong data is lacking for the use of DOACs in the setting of CVST. However, DOACs are an acceptable alternative to warfarin especially when patients have a strong aversion to warfarin therapy. Some patients may require extended or indefinite anticoagulation therapy when they have prior thrombotic events, rheumatologic, or genetic thrombophilias. 
Other instances to consider anticoagulation are in patients with embolic appearing strokes with heart failure, specifically with LVEF $<40 \%$. This is a controversial topic, but some vascular neurologists utilize this approach based on interpretation of the available data (158). Clinicians should employ anticoagulation therapy in APS related strokes.

Recent data exists demonstrating harm in patients receiving empiric anticoagulation who have embolic strokes of undetermined source (ESUS) (159, 160). There exists no strong data to dictate what to do when young patients have recurrent embolic strokes. When young patients have recurrent embolic stroke events despite optimal medical therapy (i.e., antithrombotic therapy, etc.) and lifestyle management has been optimized (e.g., discontinuance of smoking, healthy diet, regular exercise), one may consider empiric anticoagulation therapy, but this is purely opinion, and no data supports this practice.

Healthcare providers and teams must educate patients and their family/ caregiver(s) during the initial stroke diagnosis and throughout longitudinal follow up. If clinical pharmacists are available, their specialized skills and expertise will further help with patient education in terms of the medication management and adherence counseling. Diet modifications and a nutritional plan are paramount. Nutritionists, when available, may aid with this.

Stroke patients who have atherosclerotic disease require statin therapy. Furthermore, statins lowered recurrent vascular events in young patients with cryptogenic strokes (161). In atherosclerotic disease, the benefit of high intensity statins (e.g., atorvastatin $80 \mathrm{mg}$, rosuvastatin $40 \mathrm{mg}$ ) clearly reduces recurrent stroke risk $(152,162)$. The recent Treat Stroke to Target (TST) clinical trial, demonstrated a benefit in targeting an LDL goal $<70 \mathrm{mg} / \mathrm{dl}$ (163). Clinicians should prescribe atorvastatin $80 \mathrm{mg}$ daily or rosuvastatin $40 \mathrm{mg}$ daily. At 1 to 3 months post stroke repeat a lipid panel. If LDL not at goal, add ezetimibe. If patients are refractory to standard treatments, one can consider adding a PSCK-9 Inhibitor (164).

Hypertension is another treatable traditional vascular risk factor that is a prime target for secondary stroke prevention. The American Heart Association recommends long-term blood pressure goals less than 140/90mmHg in non-diabetic patients and less than $130 / 90 \mathrm{mmHg}$ in diabetic patients $(165,166)$.

Diabetes is another important vascular risk factor to consider. In comparison to older patients, diabetes is less prevalent in young stroke patients. However, the young patients who do have diabetes demonstrate a 2 to 6 -fold increased stroke risk (28). Diabetes education and an optimized diet and pharmacologic intervention plan is vital. The goal is HgbAlC less than $7 \%$ as recommended by the AHA (76). Additionally, AHA recommends diabetic diets with a low glycemic index.

Sedentary lifestyle is a risk factor for multiple cardiovascular conditions (167). Guidelines recommend stroke patients perform at least 30 minutes of moderate exercise at least 3 days a week (28). DASH and Mediterranean diets show cardiovascular benefits $(168,169)$.

Smoking cessation is extremely important in all stroke patients including young stroke patients $(170,171)$. This includes vaping, e-cigarettes and other similar "tobacco replacement" products. Additionally, counseling to stop excessive alcohol consumption, as well as to stop all recreational drug use is warranted.

Carotid endarterectomy (CEA) and/or carotid artery stenting (CAS) are recommended in stroke patients who have suffered a stroke or TIA referable to 
symptomatic severe ipsilateral extracranial carotid artery stenosis. Severe carotid stenosis is defined as 70-99\% stenosed. The risk/benefit favors intervention when perioperative morbidity and mortality is $6 \%$ or less (28). Depending on the age, gender, and medical comorbidities intervention, intervention can be considered for moderate stenosis (50-69\%) (76). Table 1 outlines some special considerations for treatment intervention among select young-onset stroke patients (172-174).

\section{CONCLUSION}

Stroke in young adults remains a growing problem in the United States and worldwide. Young adults are a heterogeneous group of patients whose stroke etiology profile is much different than older stroke patients. Such individuals require a careful clinical evaluation to better understand the stroke mechanism and thus optimize the secondary stroke prevention plan. A technique of evaluation from the 'heart to head' provides a framework for the clinical approach to these unique patients.

Acknowledgment: Dr. Cole was partially supported by the NIH/NINDS (Grants: R01-NS114045; R01-NS100178; R01-NS105150), an American Heart Association (AHA)-Bayer Discovery Grant (Grant 17IBDG33700328), the AHA Cardiovascular Genome-Phenome Study (Grant-15GPSPG23770000), and the U.S. Department of Veterans Affairs.

Conflict of interest: The authors declare no potential conflict of interest with respect to research, authorship and/or publication of this chapter.

Copyright and permission statement: The authors confirm that the materials included in this chapter do not violate copyright laws. Where relevant, appropriate permissions have been obtained from the original copyright holder(s), and all original sources have been appropriately acknowledged or referenced.

\section{REFERENCES}

1. Ovbiagele B. Nationwide trends in in-hospital morality amount patients with stroke. Stroke 2010; 41(8):1748-54. https://doi.org/10.1161/STROKEAHA.110.585455

2. Jauch EC, Saver JL, Adams HP Jr, Bruno A, Connors JJ, Demaerschalk BM, et al. Guidelines for the early management of patients with acute ischemic stroke: a guideline for healthcare professionals from the American Heart Association/American Stroke Association. Stroke 2013;44 (3):870-947. https:// doi.org/10.1161/STR.0b013e318284056a

3. Ramirez L, Kim-Tenser MA, Sanossian N, Cen S, Wen G, He S, et al. Trends in acute ischemic stroke hospitalizations in the United States. J Am Heart Assoc 2016;5(5):e003233. https://doi.org/10.1161/ JAHA.116.003233

4. Lee LK, Bateman BT, Wang S, Schumacher HC, Pile-Spellman J, Saposnik G et al. Trends in the hospitalization of ischemic stroke in the United States. Int J Stroke 2012;7(3):195-201. https://doi. org/10.1111/j.1747-4949.2011.00700.x 
5. Pathak EB, Sloan MA. Recent racial/ethnic disparities in stroke hospitalizations and outcomes for young adults in Florida. Neuroepidemiology 2009;32(4):302-11. https://doi.org/10.1159/000208795

6. Kissela BM, Khoury JC, Alwell K, Moomaw CJ, Woo D, Adeoye O, et al. Age at stroke: temporal trends in stroke incidence in a large, biracial population. Neurology 2012;79(17):1781-7. https://doi. org/10.1212/WNL.0b013e318270401d

7. Towfighi A, Ovbiagele B, Saver JL. Therapeutic milestone: stroke declines from the second to the third leading organ- and disease-specific cause of death in the United States. Stroke 2010;41(3):499-503. https://doi.org/10.1161/STROKEAHA.109.571828

8. Towfighi A, Saver JL. Stroke declines from third to fourth leading cause of death in the United States: historical perspective and challenges ahead. Stroke 2011;42(8):2351-5. https://doi.org/10.1161/ STROKEAHA.111.621904

9. Ovbiagele B, Markovic D, Towfighi A. Recent age- and gender-specific trends in mortality during stroke hospitalization in the United States. Int J Stroke 2011;6(5):379-87. https://doi. org/10.1111/j.1747-4949.2011.00590.x

10. The National Institute of Neurological Disorders and Stroke rt-PA Stroke Study Group. Tissue plasminogen activator for acute ischemic stroke. N Engl J Med. 1995;333(24):1581-7. https://doi. org/10.1056/NEJM199512143332401

11. Hacke W, Kaste M, Bluhmki E, Brozman M, Dávalos A, Guidetti D, et al. Thrombolysis with Alteplase 3 to 4.5 Hours after Acute Ischemic Stroke. N Engl J Med. 2008. 359(13):1317-29. https://doi. org/10.1056/NEJMoa0804656

12. Berkhemer OA, Fransen PSS, Beumer D, van den Berg LA, Lingsma HF, Yoo AJ, et al. A randomized trial of intraarterial treatment for acute ischemic stroke. N Engl J Med 2015;372(1):11-20. https://doi. org/10.1056/NEJMoal411587

13. Goyal M, Demchuk AM, Menon BK, Eesa M, Rempel JL, Thornton J, et al. Randomized assessment of rapid endovascular treatment of ischemic stroke. N Engl J Med 2015;372(11): 1019-30. https://doi. org/10.1056/NEJMoal414905

14. Campbell BC, Mitchell PJ, Kleinig TJ, Dewey HM, Churilov L, Yassi N et al. Endovascular therapy for ischemic stroke with perfusion-imaging selection. N Engl J Med 2015;372(11):1009-18. https://doi. org/10.1056/NEJMoal414792

15. Saver JL, Goyal M, Bonafe A, Diener HC, Levy EI, Pereira VM, et al. Stent-retriever thrombectomy after intravenous t-PA vs. t-PA alone in stroke. N Engl J Med 2015;372(24): 2285-95. https://doi. org/10.1056/NEJMoal415061

16. Jovin TG, Chamorro A, Cobo E, de Miquel MA, Molina CA, Rovira A, et al. Thrombectomy within 8h after symptom onset in ischemic stroke. N Engl J Med 2015;372(24):2296-306. https://doi. org/10.1056/NEJMoal503780

17. Bracard S, Ducrocq X, Mas JL, Soudant M, Oppenheim C, Moulin T, et al. Mechanical thrombectomy after intravenous alteplase versus alteplase alone after stroke (THRACE): a randomized controlled trial. Lancet Neurol 2016;15(11):1138-47. https://doi.org/10.1016/S1474-4422(16)30177-6

18. Nogueira RG, Jadhav AP, Haussen DC, Bonafe A, Budzik RF, Bhuva P, et al. Thrombectomy 6 to 24 hours after stroke with a mismatch between deficit and infarct. N Engl J Med 2018;378(1):11-21. https://doi.org/10.1056/NEJMoa1706442

19. Albers GW, Marks MP, Kemp S, Christensen S, Tsai JP, Ortega-Gutierrez S, et al. Thrombectomy for stroke at 6 to 16 hours with selection by perfusion imaging. N Engl J Med 2018;378(8):708-18. https://doi.org/10.1056/NEJMoal713973

20. Schwamm LH, Wu O, Song SS, Latour LL, Ford AL, Hsia AW, et al. Intravenous thrombolysis in unwitnessed stroke onset: MR WITNESS trial results. Ann Neurol. 2018;83(5):980-93. https://doi. org/10.1002/ana.25235

21. Thomalla G, Simonsen CZ, Boutitie F, Andersen G, Berthezene Y, Cheng B, et al. MRI-guided thrombolysis for stroke with unknown time of onset. N Engl J Med. 2018;379(7):611-22. https://doi. org/10.1056/NEJMoal804355

22. Ma H, Campbell BC, Parsons MW, Churilov L, Levi CR, Hsu C, et al. Thrombolysis guided by perfusion imaging up to 9 hours after onset of stroke. N Engl J Med. 2019;380(19):1795-803. https://doi. org/10.1056/NEJMoal813046 
23. Campbell BC, Ma H, Ringleb PA, Parsons MW, Churilov L, Bendszus M, et al. Extending thrombolysis to 4.5-9 h and wake-up stroke using perfusion imaging: A systematic review and metaanalysis of individual patient data. Lancet. 2019;394(10193):139-47. https://doi.org/10.1016/ S0140-6736(19)31053-0

24. Ali-Ahmed F, Federspiel JJ, Liang L, Xu H, Sevilis T, Hernandez AF, et al. Intravenous Tissue Plasminogen Activator in Stroke Mimics. Circ Cardiovasc Qual Outcomes. 2019;12(8):e005609. https://doi.org/10.1161/CIRCOUTCOMES.119.005609

25. Hofmeijer J, Kappelle LJ, Algra A, Amelink GJ, van Gijn J, van der Worp HB, et al. Surgical decompression for space-occupying cerebral infarction (the hemicraniectomy after middle cerebral artery infarction with life-threatening edema trial [hamlet]): a multicentre, open, randomised trial. Lancet Neurol. 2009;8(4)::326-33. https://doi.org/10.1016/S1474-4422(09)70047-X

26. Sheth KN, Elm JJ, Molyneaux BJ, Hinson H, Beslow LA, Sze GK, et al. Safety and efficacy of intravenous glyburide on brain swelling after large hemispheric infarction (GAMES-RP): A randomised, double-blind, placebo-controlled phase 2 trial. Lancet Neurol. 2016;15(11):1160-9. https://doi. org/10.1016/S1474-4422(16)30196-X

27. CHARM trial (enrolling): https://clinicaltrials.gov/ct2/show/NCT02864953 [Accessed on 24 April 2021]

28. Smajlović D. Strokes in young adults: epidemiology and prevention. Vasc Health Risk Manag. 2015;11:157-64. https://doi.org/10.2147/VHRM.S53203

29. Aarnio K, Haapaniemi E, Melkas S, Kaste M, TatlisumakT, Putaala J. Long-term mortality after first ever and recurrent stroke in young adults. Stroke. 2014;45(9):2670-6. https://doi.org/10.1161/ STROKEAHA.114.005648

30. Ferro JM, Massaro AR, Mas J-L. Aetiological diagnosis of ischaemic stroke in young adults. Lancet Neurol. 2010;9(11):1085-96. https://doi.org/10.1016/S1474-4422(10)70251-9

31. Putaala J, Metso AJ, Metso TM, Konkola N, Kraemer Y, Haapaniemi E, et al. Analysis of 1008 consecutive patients aged 15 to 49 with first-ever ischemic stroke: the Helsinki young stroke registry. Stroke. 2009;40(4):1195-203. https://doi.org/10.1161/STROKEAHA.108.529883

32. Cerrato P, Grasso M, Imperiale D, Priano L, Baima C, Giraudo M, et al. Stroke in young patients: etiopathogenesis and risk factors in different age classes. Cerebrovasc Dis. 2004;18(2):154-9. https:// doi.org/10.1159/000079735

33. Bogousslavsky J, Pierre P. Ischemic stroke in patients under age 45. Neurol Clin. 1992;10(1):113-24. https://doi.org/10.1016/S0733-8619(18)30236-6

34. Gautier JC, Pradat-Diehl P, Loron P, Lechat P, Lascault G, Juillard JB, et al. Cerebral vascular accidents in young subjects. A study of 133 patients 9 to 45 years of age. Rev Neurol (Paris). 1989;145(6-7):437-42.

35. Ducrocq X, Lacour JC, Debouverie M, Bracard S, Girard F, Weber M, et al. Cerebral ischemic accidents in young subjects. A prospective study of 296 patients aged 16 to 45 year.Rev Neurol (Paris). 1999;155(8):575-82.

36. Lisovoski F, Rousseaux P. Cerebral infarction in young people: a study of 148 patients with early cerebral angiography. J Neurol Neurosurg Psychiatry. 1991;54(7):576-9. https://doi.org/10.1136/ jnnp. 54.7.576

37. Putaala J, Haapaniemi E, Metso AJ, Metso TM, Artto V, Kaste M, et al. Recurrent ischemic events in young adults after first-ever ischemic stroke. Ann Neurol. 2010;68(5):661-71. https://doi. org/10.1002/ana.22091

38. Kappelle LJ, Adams HP Jr, Heffner ML, Torner JC, Gomez F, Biller J. Prognosis of young adults with ischemic stroke. A long-term follow-up study assessing recurrent vascular events and functional outcome in the Iowa registry of stroke in young adults. Stroke. 1994;25(7):1360-5. https://doi. org/10.1161/01.STR.25.7.1360

39. Putaala J, Curtze S, Hiltunen S, Tolppanen H, Kaste M, Tatlisumak T. Causes of death and predictors of 5-year mortality in young adults after first-ever ischemic stroke: the Helsinki young stroke registry. Stroke. 2009;40(8):2698-703. https://doi.org/10.1161/STROKEAHA.109.554998

40. Mokri B, Sundt TM, Houser OW, Piepgras DG. Spontaneous dissection of the cervical internal carotid artery. Ann Neurol 1986;19(2):126-38. https://doi.org/10.1002/ana.410190204 
41. Schievink WI, Meyer FB, Parisi JE, Wijdicks EF. Fibromuscular dysplasia of the internal carotid artery associated with alpha-1-antitrypsin deficiency. Neurosurgery. 1998;43(2):229-33. https://doi. org/10.1097/00006123-199808000-00022

42. D’Anglejean-Chatillon J, Ribeiro V, Mas JL, Youl BD, Bousser MG, et al. Migraine-a risk factor for dissection of cervical arteries. Headache. 1989;29(9):560-1. https://doi.org/10.1111/j.1526-4610.1989. hed2909560.x

43. Fisher CM. The headache and pain of spontaneous carotid dissection. Headache. 1982;22(2):60-5. https://doi.org/10.1111/j.1526-4610.1982.hed2202060.x

44. Pezzini A, Grassi M, Del Zotto E, Giossi A, Monastero R, Volta GD, et al. Migraine mediates the influence of C677T MTHFR genotypes on ischemic stroke risk with a stroke-subtype effect. Stroke. 2007;38(12):2145-51. https://doi.org/10.1161/STROKEAHA.107.491506

45. Grau AJ, Brandt T, Forsting M, Winter R, Hacke W. Infection associated cervical artery dissection: three cases. Stroke. 1997;28(2):453-5. https://doi.org/10.1161/01.STR.28.2.453

46. Grau AJ, Brandt T, Buggle F, Orberk E, Mytilineos J, Werle E, et al. Association of cervical artery dissection with recent infection. Arch Neurol. 1999;56(7):851-6. https://doi.org/10.1001/ archneur.56.7.851

47. Constantinescu CS. Association of varicella-zoster virus with cervical artery dissection in 2 cases. Arch Neurol. 2000;57(3):427. https://doi.org/10.1001/archneur.57.3.427

48. Wiebers DO, Mokri B. Internal carotid artery dissection after childbirth. Stroke. 1985;16(6):956-9. https://doi.org/10.1161/01.STR.16.6.956

49. Mas J-L, Bousser M-G, Corone P, Touboul PJ. Dissecting aneurysm of the extracranial vertebral arteries and pregnancy. Rev Neurol (Paris). 1987;143(1):761-4.

50. Debette S. Pathophysiology and risk factors of cervical artery dissection: what have we learnt from large hospital-based cohorts? Curr Opin Neurol 2014;27(1):20-8. https://doi.org/10.1097/ WCO.0000000000000056

51. Metso TM, Tatlisumak T, Debette S, Dallongeville J, Engelter ST, Lyrer PA, et al., Migraine in cervical artery dissection and ischemic stroke patients. Neurology 2012;78(16):1221-8. https://doi. org/10.1212/WNL.0b013e318251595f

52. Debette S, Metso T, Pezzini A, Abboud S, Metso A, Leys D et al., Association of vascular risk factors with cervical artery dissection and ischemic stroke in young adults. Circulation 2011;123(14): 1537-44. https://doi.org/10.1161/CIRCULATIONAHA.110.000125

53. Cuvinciuc V, Viallon M, Momjian-Mayor I, Sztajzel R, Pereira VM, Lovblad Ket al. 3D fat-saturated T1 SPACE sequence for the diagnosis of cervical artery dissection. Neuroradiology. 2013;55(5):595-602. https://doi.org/10.1007/s00234-013-1141-1

54. Kirton A, Crone M, Benseler S, Mineyko A, Armstrong D, Wade A, et al. Fibromuscular dysplasia and childhood stroke. Brain. 2013;136(6):1846-56. https://doi.org/10.1093/brain/awt111

55. Slovut DP, Olin JW. Fibromuscular dysplasia. N Engl J Med. 2004;350(18):1862-71. https://doi. org/10.1056/NEJMra032393

56. Touze E, Oppenheim C, Trystram D, Nokam G, Pasquini M, Alamowitch S, et al. Fibromuscular dysplasia of cervical and intracranial arteries. Int J Stroke. 2010;5(4):296-305. https://doi. org/10.1111/j.1747-4949.2010.00445.x

57. Hsu SW, Chaloupka JC, Fattal D. Rapidly progressive fatal bihemispheric infarction secondary to Moyamoya syndrome in association with Graves thyrotoxicosis. AJNR Am J Neuroradiol. 2006;27(3): 643-7.

58. Dähnert W. Radiology Review Manual. Lippincott Williams \& Wilkins. 2007;ISBN: 0781766206.

59. Reeder MM, Bradley WG. Reeder and Felson's gamuts in radiology, comprehensive lists of roentgen differential diagnosis. Springer. 2003;ISBN: 0387955887. https://doi.org/10.1007/b97426

60. Aviv RI, Benseler SM, Silverman ED, Tyrrell PN, Deveber G, Tsang LM et-al. MR imaging and angiography of primary CNS vasculitis of childhood. AJNR Am J Neuroradiol. 2006;27(1):192-9.

61. Jiang T, Perry A, Dacey RG, Zipfel GJ, Derdeyn CP. Intracranial atherosclerotic disease associated with moyamoya collateral formation: histopathological findings. J. Neurosurg. 2013;118(5):1030-4. https://doi.org/10.3171/2013.1.JNS12565

62. Lazzaro MA, Cochran EJ, Lopes DK, Prabhakaran S. Moyamoya syndrome in an adult with essential thrombocythemia. Neurol Int. 2011;3(1):e3. https://doi.org/10.4081/ni.2011.e3 
63. Hua le H, Dodd RL, Schwartz NE. Concurrent stenoocclusive disease of intracranial and extracranial arteries in a patient with polycythemia vera. Case Rep Med. 29;2012: 151767. https://doi. org/10.1155/2012/151767

64. Kornblihtt LI, Cocorullo S, Miranda C, Lylyk P, Heller PG, Molinas FC. Moyamoya syndrome in an adolescent with essential thrombocythemia: successful intracranial carotid stent placement. Stroke. 2005;36(8):E71-3. https://doi.org/10.1161/01.STR.0000174193.89864.55

65. Susac JO, Murtagh FR, Egan RA, Berger JR, Bakshi R, Lincoff N, et al. MRI findings in Susac's syndrome. Neurology 2003;61(12):1783-7. https://doi.org/10.1212/01.WNL.0000103880.29693.48

66. Bousser MG, Ferro JM. Cerebral venous thrombosis: An update. Lancet Neurol. 2007;6(2):162-170. https://doi.org/10.1016/S1474-4422(07)70029-7

67. Star M, Flaster M. Advances and controversies in the management of cerebral venous thrombosis. Neurologic Clinics. 2013;31(3):765-83. https://doi.org/10.1016/j.ncl.2013.03.013

68. Ferro JM, Canhão P, Stam J, Bousser MG, Barinagarrementeria F, ISCVT investigators. Prognosis of cerebral vein and dural sinus thrombosis: Results of the international study on cerebral vein and dural sinus thrombosis (ISCVT). Stroke. 2004;35(3):664-70. https://doi.org/10.1161/01. STR.0000117571.76197.26

69. Coutinho JM, Zuurbier SM, Aramideh M, Stam J. The incidence of cerebral venous thrombosis: A cross-sectional study. Stroke. 2012;43(12):3375-3377. https://doi.org/10.1161/ STROKEAHA. 112.671453

70. Coutinho JM, Ferro JM, Canhão P, Barinagarrementeria F, Cantú C, Bousser MG, Stam J. Cerebral venous and sinus thrombosis in women. Stroke. 2009;40(7):2356-61. https://doi.org/10.1161/ STROKEAHA.108.543884

71. Saposnik G, Barinagarrementeria F, Brown RD Jr, Bushnell CD, Cucchiara B, Cushman M, et al. Diagnosis and management of cerebral venous thrombosis a statement for healthcare professionals from the American Heart Association/ American Stroke Association. Stroke. 2011;42(4):1158-92. https://doi.org/10.1161/STR.0b013e31820a8364

72. Ferro JM, Canhão P, Stam J, Bousser MG, Barinagarrementeria F, Massaro A, et al. Delay in the diagnosis of cerebral vein and dural sinus thrombosis influence on outcome. Stroke. 2009;40(9):3133-8. https://doi.org/10.1161/STROKEAHA.109.553891

73. De Bruijn SF, Stam J. Randomized, placebo-controlled trial of anticoagulant treatment with low-molecular weight heparin for cerebral sinus thrombosis. Stroke. 1999;30:484-8. https://doi.org/10.1161/01. STR.30.3.484

74. Cotter PE, Martin PJ, Ring L, Warburton EA, Belham M, Pugh PJ. Incidence of atrial fibrillation detected by implantable loop recorders in unexplained stroke. Neurology 2013;80(17):1546-50. https://doi.org/10.1212/WNL.0b013e31828f1828

75. Bassetti C, Carruzzo A, Sturzenegger M, Tuncdogan E. Recurrence of cervical artery dissection: a prospective study of 81 patients. Stroke 1996;27(10):1804-7. https://doi.org/10.1161/01. STR.27.10.1804

76. Powers WJ, Rabinstein AA, Ackerson T, Adeoye OM, Bambakidis NC, Becker K, et al.2018 Guidelines for the early management of patients with acute ischemic stroke: a guideline for healthcare professionals from the American Heart Association/American Stroke Association. Stroke 2018;49(3):e46-el10. https://doi.org/10.1161/STR.0000000000000163

77. Khariton Y, House JA, Comer L, Coggins TR, Magalski A, Skolnick DG, et al. Impact of transesophageal echocardiography on management in patients with suspected cardioembolic stroke. Am J Cardiol. 2014;114(12):1912-6. https://doi.org/10.1016/j.amjcard.2014.09.035

78. Furlan AJ, Reisman M, Massaro J, Mauri L, Adams H, Albers GW, et al. Closure or medical therapy for cryptogenic stroke with patent foramen ovale. N Engl J Med 2012;366(11):991-9. https://doi. org/10.1056/NEJMoal009639

79. Carroll JD, Saver JL, Thaler DE, Smalling RW, Berry S, MacDonald LA, et al. Closure of patent foramen ovale versus medical therapy after cryptogenic stroke. N Engl J Med 2013;368(12):1092-100. https:// doi.org/10.1056/NEJMoal301440

80. Meier B, Kalesan B, Mattle HP, Khattab AA, Hildick-Smith D, Dudek D. Percutaneous closure of patent foramen ovale in cryptogenic embolism. N Engl J Med 2013;368(12):1083-91. https://doi. org/10.1056/NEJMoal211716 
81. Mas JL, Derumeaux G, Guillon B, Massardier E, Hosseini H, Mechtouff L, et al. Patent foramen ovale closure or anticoagulation vs. antiplatelets after stroke. N Engl J Med 2017;377(11):1011-1021. https://doi.org/10.1056/NEJMoal705915

82. Søndergaard L, Kasner SE, Rhodes JF, Andersen G, Iversen HK, Nielsen-Kudsk JE, et al. Patent foramen ovale closure or antiplatelet therapy for cryptogenic stroke. N Engl J Med 2017;377(11): 1033-42. https://doi.org/10.1056/NEJMoal707404

83. Saver JL, Carroll JD, Thaler DE, Smalling RW, MacDonald LA, Marks DS et al. Long-term outcomes of patent foramen ovale closure or medical therapy after stroke. N Engl J Med 2017;377(11):1022-32. https://doi.org/10.1056/NEJMoal610057

84. Kittner SJ, Stern BJ, Wozniak M, Buchholz DW, Earley CJ, Feeser BR, et al. Cerebral infarction in young adults: the Baltimore-Washington Cooperative Young Stroke Study. Neurology 1998;50(4):890-4. https://doi.org/10.1212/WNL.50.4.890

85. Mackay MT, Wiznitzer M, Benedict SL, Lee KJ, Deveber GA, Ganesan V, et al. Arterial ischemic stroke risk factors: the International Pediatric Stroke Study. Ann Neurol 2011;69(1):130-40. https://doi. org/10.1002/ana.22224

86. Rodan L, McCrindle BW, Manlhiot C, MacGregor DL, Askalan R, Moharir M, et al. Stroke recurrence in children with congenital heart disease. Ann Neurol 2012;72(1):103-11. https://doi.org/10.1002/ ana.23574

87. Dowling MM, Hynan LS, Lo W, Licht DJ, McClure C, Yager JY, et al. International Paediatric Stroke Study: stroke associated with cardiac disorders. Int J Stroke 2013;8(Suppl A100):39-44. https://doi. org/10.1111/j.1747-4949.2012.00925.x

88. Hoffmann A, Chockalingam P, Balint OH, Dadashev A, Dimopoulos K, Engel R, et al. Cerebrovascular accidents in adult patients with congenital heart disease. Heart 2010;96(15):1223-6. https://doi. org/10.1136/hrt.2010.196147

89. Love BB, Biller J, Jones MP, Adams HP Jr, Bruno A. Cigarette smoking. A risk factor for cerebral infarction in young adults. Arch Neurol. 1990;47(6):693-8. https://doi.org/10.1001/ archneur.1990.00530060107027

90. Sloan MA, Kittner SJ, Feeser BR, Gardner J, Epstein A, Wozniak MA, et al. Illicit drug associated ischemic stroke in the Baltimore Washington Young Stroke Study. Neurology. 1998;50(6):1688-93. https://doi.org/10.1212/WNL.50.6.1688

91. Sundell L, Salomaa V, Vartiainen E, Poikolainen K, Laatikainen T. Increased stroke risk is related to a binge drinking habit. Stroke. 2008;39(12):3179-84. https://doi.org/10.1161/STROKEAHA.108.520817

92. Hillbom M, Numminen H. Alcohol and stroke: pathophysiologic mechanisms. Neuroepidemiology 1998;17(6):281-7. https://doi.org/10.1159/000026181

93. Keogh CF, Andrews GT, Spacey SD, Forkheim KE, Graeb DA. Neuroimaging features of heroin inhalation toxicity: "chasing the dragon". AJR Am J Roentgenol. 2003;180(3):847-50. https://doi. org/10.2214/ajr.180.3.1800847

94. Cheng YC, Ryan KA, Qadwai SA, Shah J, Mary Sparks MJ, Wozniak MA, et al. Cocaine use and risk of ischemic stroke in young adults. Stroke 2016;47(4):918-22. https://doi.org/10.1161/ STROKEAHA.115.011417

95. Rumalla K, Reddy AY, Mittal MK. Recreational marijuana use and acute ischemic stroke: a populationbased analysis of hospitalized patients in the United States. J Neurol Sci 2016;364:191-6. https://doi. org/10.1016/j.jns.2016.01.066

96. Bousser MG, Welch KM. Relation between migraine and stroke. Lancet Neurol. 2005;4(9):533-42. https://doi.org/10.1016/S1474-4422(05)70164-2

97. Schurks M, Rist PM, Bigal ME, Buring JE, Lipton RB, Kurth T. Migraine and cardiovascular disease: systematic review and meta-analysis. BMJ. 2009;339:b3914. https://doi.org/10.1136/bmj.b3914

98. Etminan M, Takkouche B, Isorna FC, Samii A. Risk of ischaemic stroke in people with migraine: systematic review and meta-analysis of observational studies. BMJ. 2005;330:63. https://doi.org/10.1136/ bmj.38302.504063.8F

99. Curtis KM, Mohllajee AP, Peterson HB. Use of combined oral contraceptives among women with migraine and nonmigrainous headaches: a systematic review. Contraception. 2006;73(2):189-94 https://doi.org/10.1016/j.contraception.2005.08.009 
100. Spector JT, Kahn SR, Jones MR, Jayakumar M, Dalal D, Nazarian S. Migraine headache and ischemic stroke risk: an updated meta-analysis. Am J Med 2010;123(7):612-24. https://doi.org/10.1016/j. amjmed.2009.12.021

101. Bousser MG. Estrogens, migraine, and stroke. Stroke 2004;35(11 suppl 1):2652-6. https://doi. org/10.1161/01.STR.0000143223.25843.36

102. Roach RE, Helmerhorst FM, Lijfering WM, Stijnen T, Algra A, Dekkers OM, et al. Combined oral contraceptives: the risk of myocardial infarction and ischemic stroke. Cochrane Database Syst Rev 2015;2015(8):CD011054. https://doi.org/10.1002/14651858.CD011054.pub2

103. deVeber G, Andrew M, Adams C, Bjornson B, Booth F, Buckley DJ, et al. Cerebral sinovenous thrombosis in children. N Engl JMed. 2001;345(6):417-23. https://doi.org/10.1056/NEJM200108093450604

104. Ferro JM, Canhão P, Bousser MG, Stam J, Barinagarrementeria F, ISCVT investigators. Cerebral vein and dural sinus thrombosis in elderly patients. Stroke. 2005;36(9):1927-32. https://doi.org/10.1161/01. STR.0000177894.05495.54

105. Edris F, Kerner CM, Feyles V, Leung A, Power S. Successful management of an extensive intracranial sinus thrombosis in a patient undergoing IVF: Case report and review of the literature. Fertility and Sterility. 2007;88(3): 705.e9-e14. https://doi.org/10.1016/j.fertnstert.2006.12.024

106. Ameri A, Bousser MG. Headache in cerebral venous thrombosis: A study of 110 cases. Cephalalgia. 1993;13(Suppl 13):110.

107. Dentali F, Crowther M, Ageno W. Thrombophilic abnormalities, oral contraceptives, and risk of cerebral vein thrombosis: A meta-analysis. Blood. 2006;107(7):2766-73. https://doi.org/10.1182/ blood-2005-09-3578

108. de Bruijn SF, Stam J, Koopman MM, Vandenbroucke JP. Case-control study of risk of cerebral sinus thrombosis in oral contraceptive users and in carriers of hereditary prothrombotic conditions. BMJ. 1998;316(7131):589-92. https://doi.org/10.1136/bmj.316.7131.589

109. Martinelli I, Sacchi E, Landi G, Taioli E, Duca F, Mannucci PM. High risk of cerebral-vein thrombosis in carriers of a prothrombin-gene mutation and in users of oral contraceptives. N Engl J Med. 1998;338(25):1793-7. https://doi.org/10.1056/NEJM199806183382502

110. Swartz RH, Cayley ML, Foley N, Ladhani NNN, Leffert L, Bushnell C, et al. The incidence of pregnancy-related stroke: a systematic review and meta-analysis. IntJ Stroke 2017;12(7):687-97. https:// doi.org/10.1177/1747493017723271

111. Kamel H, Navi BB, Sriram N, Hovsepian DA, Devereux RB, Elkind, MSV. Risk of a thrombotic event after the 6 week post partum period. N Engl J Med. 2014;370(14):1307-15. https://doi.org/10.1056/ NEJMoal311485

112. van Alebeek ME, de Heus R, Tuladhar AM, de Leeuw FE. Pregnancy and ischemic stroke: a practical guide to management. Curr Opin Neurol 2018;31(1):44-51. https://doi.org/10.1097/ WCO.0000000000000522

113. de Sousa DA, Canhão P, Crassard I, Coutinho J, Arauz A, Conforto A, et al. Safety of Pregnancy After Cerebral Venous Thrombosis: Results of the ISCVT (International Study on Cerebral Vein and Dural Sinus Thrombosis)-2 PREGNANCY Study. Stroke 2017;48(11):3130-33. https://doi.org/10.1161/ STROKEAHA.117.018829

114. Morris JG, Singh S, Fisher M. Testing for inherited rhrombophilias in arterial stroke: can it cause more harm than good? Stroke. 2010;41(12):2985-90. https://doi.org/10.1161/STROKEAHA.110.595199

115. Pezzini A, Grassi M, Iacoviello L, Del Zotto E, Archetti S, Giossi A, et al. Inherited thrombophilia and stratification of ischaemic stroke risk among users of oral contraceptives. J Neurol Neurosurg Psychiatry 2007;78(3):271-6. https://doi.org/10.1136/jnnp.2006.101675

116. PezziniA, Grassi M, Del Zotto E, Archetti S, Spezi R, Vergani V, et al. Cumulative effect of predisposing genotypes and their interaction with modifiable factors on the risk of ischemic stroke in young adults. Stroke 2005;36(3):533-9. https://doi.org/10.1161/01.STR.0000155741.31499.c2

117. Gómez-Puerta JA, Cervera R. Diagnosis and classification of the antiphospholipid syndrome. J Autoimmune. 2014;48-49:20-5. https://doi.org/10.1016/j.jaut.2014.01.006

118. Kim Y, Kim SY. Antiphospholipid Antibody and Recurrent Ischemic Stroke: A Systematic Review and Meta-Analysis. Stroke. 2020 Dec;51(12):3728-32. https://doi.org/10.1161/STROKEAHA. 120.030431 
119. Canhão P, Ferro JM, Lindgren AG, Bousser MG, Stam J, Barinagarrementeria F, ISCVT investigators. Causes and predictors of death in cerebral venous thrombosis. Stroke. 2005;36(8):1720-5. https:// doi.org/10.1161/01.STR.0000173152.84438.1c

120. Deschiens MA, Conard J, Horellou MH, Ameri A, Preter M, Chedru F, et al. Coagulation studies, factor $\mathrm{V}$ Leiden, and anticardiolipin antibodies in 40 cases of cerebral venous thrombosis. Stroke. 1996;27(10):1724-30. https://doi.org/10.1161/01.STR.27.10.1724

121. Reuner KH, Ruf A, Grau A, Rickmann H, Stolz E, Jüttler E, et al. Prothrombin gene G20210 $\rightarrow$ A transition is a risk factor for cerebral venous thrombosis. Stroke. 1998;29(9):1765-9. https://doi. org/10.1161/01.STR.29.9.1765

122. Weih M, Vetter B, Castell S, et al. Hereditary thrombophilia in cerebral venous thrombosis. Cerebrovasc Dis. 2000;10(2):161-2. https://doi.org/10.1159/000016049

123. Ludemann P, Nabavi DG, Junker R, Wolff E, Papke K, Buchner H, et al. Factor V Leiden mutation is a risk factor for cerebral venous thrombosis: A case-control study of 55 patients. Stroke. 1998;29(12):2507-10. https://doi.org/10.1161/01.STR.29.12.2507

124. Zuber M, Toulon P, Marnet L, Mas JL. Factor V Leiden mutation in cerebral venous thrombosis. Stroke. 1996;27(10):1721-3. https://doi.org/10.1161/01.STR.27.10.1721

125. Kivioja R, Pietilä A, Martinez-Majander N, Gordin D, Havulinna AS, Salomaa V, et al. Risk factors for early-onset ischemic stroke: a case-control study. J Am Heart Assoc 2018;7(21): e009774. https://doi. org/10.1161/JAHA.118.009774

126. Bright CJ, Hawkins MM, Guha J, Henson KE, Winter DL, Kelly JS, et al. Risk of cerebrovascular events in 178962 five-year survivors of cancer diagnosed at 15 to39 years of age: the TYACSS (Teenage and Young Adult Cancer Survivor Study). Circulation 2017;135(13): 1194-1210. https://doi.org/10.1161/ CIRCULATIONAHA.116.025778

127. Kim AW, Trobe JD. Syndrome simulating pseudotumor cerebri caused by partial transverse venous sinus obstruction in metastatic prostate cancer. A J Ophthalmol. 2000;129(2):254-6. https://doi. org/10.1016/S0002-9394(99)00326-8

128. Meininger V, James JM, Rio B, Zittoun R. Dural venous sinus occlusions in hemopathies [in French]. Rev Neurol (Paris). 1985;141(3):228-33

129. Raizer JJ, DeAngelis LM. Cerebral sinus thrombosis diagnosed by MRI and MR venography in cancer patients. Neurology. 2000;54(6):1222-6. https://doi.org/10.1212/WNL.54.6.1222

130. Rogers LR. Cerebrovascular complications in patients with cancer. Semin Neurol. 2004;24(4):453-60. https://doi.org/10.1055/s-2004-861539

131. Grau AJ, Urbanek C, Palm F. Common infections and the risk of stroke. Nat Rev Neurol. 2010;6(12): 681-94. https://doi.org/10.1038/nrneurol.2010.163

132. Heikinheimo T, Broman J, Haapaniemi E, Kaste M, Tatlisumak T, Putaala J. Preceding and poststroke infections in young adults with first-ever ischemic stroke: effect on short-term and long-term outcomes. Stroke 2013;44(12):3331-7. https://doi.org/10.1161/STROKEAHA.113.002108

133. Benjamin LA, Bryer A, Emsley HC, Khoo S, Solomon T, Connor MD. HIV infection and stroke: current perspectives and future directions. Lancet Neurol 2012;11(10): 878-90. https://doi.org/10.1016/ S1474-4422(12)70205-3

134. Carod-Artal FJ, Gascon J. Chagas disease and stroke. Lancet Neurol 2010;9(5):533-42. https://doi. org/10.1016/S1474-4422(10)70042-9

135. Wang A, Mandigo GK, Yim PD, Meyers PM, Lavine SD. Stroke and mechanical thrombectomy in patients with COVID-19: technical observations and patient characteristics. J Neurointerv Surg. 2020;12(7): 648-53. https://doi.org/10.1136/neurintsurg-2020-016220

136. Majidi S, Fifi JT, Ladner TR, Lara-Reyna J, Yaeger KA, Ymir B, et al. Emergent Large Vessel Occlusion Stroke During New York City's COVID-19 Outbreak: Clinical Characteristics and Paraclinical Findings. Stroke. 2020;51(9):2656-63. https://doi.org/10.1161/STROKEAHA.120.030397

137. Oxley TJ, Mocco J, Majidi S, Kellner CP, Shoirah H, Singh P et al. Large-vessel stroke as a presenting feature of Covid-19 in the young. N Engl J Med. 2020;382(20):660. https://doi.org/10.1056/ NEJMc2009787

138. Ntaios G, Michel P, Georgiopoulos G, Guo Y, Li W, Xiong J, et al. Characteristics and outcomes in patients with COVID-19 and acute ischemic stroke: the global COVID-19 stroke registry. Stroke. 2020;51(9):254-8. https://doi.org/10.1161/STROKEAHA.120.031208 
139. Yaghi S, Ishida K, Torres J, Grory BM, Raz E, Humbert K, et al. SARS-CoV-2 and stroke in a new york healthcare system. Stroke. 2020;51(7):2002-11. doi: 10.1161/STROKEAHA.120.030335. https:// doi.org/10.1161/STROKEAHA.120.030335

140. Katz JM, Libman RB, Wang JJ, Sanelli P, Filippi CG, Gribko M, et al. Cerebrovascular complications of COVID-19. Stroke. 2020;51(9):e227-e31. https://doi.org/10.1161/STROKEAHA.120.031265

141. Bekelis K, Missios S, Ahmad J, Labropoulos N, Schirmer CM, Calnan DR, et al. Ischemic Stroke Occurs Less Frequently in Patients With COVID-19: A Multicenter Cross-Sectional Study. Stroke. 2020;51(12):3570-76. https://doi.org/10.1161/STROKEAHA.120.031217

142. Jasne AS, Chojecka P, Maran I, Mageid R, Eldokmak M, Zhang Q, et al. Stroke Code Presentations, Interventions, and Outcomes Before and During the COVID-19 Pandemic. Stroke. 2020;51(9): 2664-73. https://doi.org/10.1161/STR.0000000000000347

143. Yesilot Barlas N, Putaala J, Waje-Andreassen U, et al. Etiology of first-ever ischaemic stroke in European young adults: the 15citiesyoung stroke study. Eur J Neurol 2013;20(11):1431-9.

144. Bersano A, Markus HS, Quaglini S, Arbustini E, Lanfranconi S, Micieli G, et al. Clinical pregenetic screening for stroke monogenic diseases: results from Lombardia GENS Registry. Stroke 2016;47(7):1702-9. https://doi.org/10.1161/STROKEAHA.115.012281

145. Tatlisumak T, Putaala J, Innilä M, Enzinger C, Metso TM, Curtze S, et al. Frequency of MELAS main mutation in a phenotype-targeted young ischemic stroke patient population. J Neurol 2016;263(2):257-62. doi:10.1007/s00415-015-7969-z. https://doi.org/10.1007/s00415-015-7969-z

146. O'Sullivan M, Jarosz JM, Martin RJ, Deasy N, Powell JF, Markus HS. MRI hyperintensities of the temporal lobe and external capsule in patients with CADASIL. Neurology. 2001;56(5):628-34. https:// doi.org/10.1212/WNL.56.5.628

147. Razvi SSM, Bone I. Single gene disorders causing ischaemic stroke. J Neurol. 2006;253:685-700. https://doi.org/10.1007/s00415-006-0048-8

148. Yamamoto Y, Craggs L, Baumann M, Kalimo H, Kalaria RN. Review: molecular genetics and pathology of hereditary small vessel diseases of the brain. Neuropathol Appl Neurobiol. 2001;37:94-113. https://doi.org/10.1111/j.1365-2990.2010.01147.x

149. Ballabio E, Bersano A, Bresolin N, Candelise L. Monogenic vessel diseases related to ischemic stroke: a clinical approach. J Cereb Blood Flow Metab. 2007;27:1649-62. https://doi.org/10.1038/ sj.jcbfm. 9600520

150. Homma S, Sacco RL, Di Tullio MR, Sciacca RR, Mohr JP. Effect of medical treatment in stroke patients with patent foramen ovale: patent foramen ovale in cryptogenic stroke study. Circulation. 2002;105(22):2625-31. https://doi.org/10.1161/01.CIR.0000017498.88393.44

151. Johnston SC, Easton JD, Farrant M, Barsan W, Conwit RA, Elm JJ, et al. Clopidogrel and aspirin in acute ischemic stroke and high-risk TIA. N Engl J Med 2018;379(3):215-255. https://doi. org/10.1056/NEJMoal800410

152. Wang Y, Wang Y, Zhao X, Liu L, Wang D, Wang C, et al. Clopidogrel with aspirin in acute minor stroke or transient ischemic attack. N Engl J Med 2013;369:11-19. https://doi.org/10.1056/ NEJMoal2 15340

153. Chimowitz MI, Lynn MJ, Derdeyn CP, Turan TN, Fiorella D, Lane BF, et al. Stenting versus aggressive medical therapy for intracranial arterial stenosis. New Eng J Med 2011;365(11):993-1003. https:// doi.org/10.1056/NEJMoal105335

154. Connolly S, Pogue J, Hart R, Pfeffer M, Hohnloser S, Chrolavicius S, et al. Clopidogrel plus aspirin versus oral anticoagulation for atrial fibrillation in the Atrial fibrillation Clopidogrel Trial with Irbesartan for prevention of Vascular Events. Lancet. 2006;367(9526):1903-12. https://doi.org/10.1016/ S0140-6736(06)68845-4

155. Patel MR, Mahaffey KW, Garg J, Pan G, Singer DE, Hacke W, et al. Rivaroxaban versus warfarin in nonvalvular atrial fibrillation. N Engl J Med. 2011;365(10):883-91. https://doi.org/10.1056/ NEJMoal009638

156. Granger CB, Alexander JH, McMurray JJ, Lopes RD, Hylek EM, Hanna M, et al. Apixaban versus warfarin in patients with atrial fibrillation. N Engl J Med. 2011;365(11):981-92. https://doi.org/10.1056/ NEJMoal 107039

157. Diener HC, Connolly SJ, Ezekowitz MD, Wallentin L, Reilly PA, Yang S, et al. Dabigatran compared with warfarin in patients with atrial fibrillation and previous transient ischaemic attack or stroke: 
a subgroup analysis of the RE-LY trial. Lancet Neurol 2010;9(12):1157-63. https://doi.org/10.1016/ S1474-4422(10)70274-X

158. Homma S, Thompson JLP, Pullicino PM, Levin B, Freudenberger RS, Teerlink JR, et al. Warfarin and aspirin in patients with heart failure and sinus rhythm. N Engl J Med 2012;366(20):1859-69. https:// doi.org/10.1056/NEJMoal202299

159. Hart RG, Sharma M, Mundl H, Kasner SE, Bangdiwala SI, Berkowitz SD, et al. Rivaroxaban for stroke prevention after embolic stroke of undetermined source. N Engl J Med 2018;378(23):2191-2201. https://doi.org/10.1056/NEJMoal802686

160. Diener HC, Sacco RL, Easton JD, Granger CB, Bernstein RA, Uchiyama S, et al. Dabigatran for Prevention of Stroke after Embolic Stroke of Undetermined Source. N Engl J Med. 2019 May 16;380(20):1906-1917. https://doi.org/10.1056/NEJMoa1813959

161. van Dongen MME, Aarnio K, Martinez-Majander N, Pirinen J, Sinisalo J, Lehto M, et al. Use of Statins After Ischemic Stroke in Young Adults and Its Association With Long-Term Outcome. Stroke. 2019 Dec;50(12):3385-92. https://doi.org/10.1161/STROKEAHA.119.026992

162. Amarenco P, Bogousslavsky J, Callahan A III, Goldstein LB, Hennerici M, Rudolph AE, et al. High-dose atorvastatin after stroke or transient ischemic attack. N Engl J Med. 2006;355(6):549-59. https://doi. org/10.1056/NEJMoa061894

163. Amarenco P, Kim JS, Labreuche J, Charles H, Abtan J, Béjot Y, et al. A Comparison of Two LDL Cholesterol Targets after Ischemic Stroke. N Engl J Med. 2020;382(1):9-19. https://doi.org/10.1056/ NEJMoal910355

164. Giugliano RP, Pedersen TR, Saver JL, Sever PS, Keech AC, Bohula EA, et al. Stroke prevention with the PCSK9 (proprotein convertase subtilisin-kexin type 9) inhibitor evolocumab added to statin in high-risk patients with stable atherosclerosis. Stroke 2020;(51):1546-54. https://doi.org/10.1161/ STROKEAHA.119.027759

165. Wright Jr JT, Williamson JD, Whelton PK, Snyder JK, Sink KM, Rocco MV, et al. A randomized trial of intensive versus standard blood-pressure control. N Engl J Med. 2015;373(22):2103-16 https://doi. org/10.1056/NEJMoa1511939

166. Gaciong Z, Siński M, Lewandowski J. Blood pressure control and primary prevention of stroke: summary of the recent clinical trial data and meta-analyses. Curr Hypertens Rep. 2013;15(6):559-74. https://doi.org/10.1007/s11906-013-0401-0

167. Butler EN, Evenson KR. Prevalence of physical activity and sedentary behavior among stroke survivors in the United States. Top Stroke Rehabil. 2014;21(3):246-55. https://doi.org/10.1310/tsr2103-246

168. He FJ, Nowson CA, MacGregor GA. Fruit and vegetable consumption and stroke: meta-analysis of cohort studies. Lancet. 2006;367(9507):320-6. https://doi.org/10.1016/S0140-6736(06)68069-0

169. Li XY, Cai XL, Bian PD, Hu LR. High salt intake and stroke: meta-analysis of the epidemiologic evidence. CNS Neurosci Ther. 2012;18(8):691-701. https://doi.org/10.1111/j.1755-5949.2012.00355.x

170. Shinton R, Beevers G. Meta-analysis of relation between cigarette smoking and stroke. BMJ. 1989;298(6676):789-94. https://doi.org/10.1136/bmj.298.6676.789

171. Feigin V, Parag V, Lawes CM, Rodgers A, Suh I, Woodward M, et al. Smoking and elevated blood pressure are the most important risk factors for subarachnoid hemorrhage in the Asia-Pacific region: an overview of 26 cohorts involving 306,620 participants. Stroke. 2005;36(7):1360-5. https://doi. org/10.1161/01.STR.0000170710.95689.41

172. Nichols FT, Jones AM, Adams RJ. Stroke prevention in sickle cell disease (STOP) study guidelines for transcranial Doppler testing. J Neuroimaging. 2001;11(4):354-62. https://doi.org/10.1111/j.15526569.2001.tb00063.x

173. Adams RJ. Lessons from the stroke prevention trial in sickle cell anemia (STOP) study. J Child Neurol. 2000;159(5):344-9. https://doi.org/10.1177/088307380001500511

174. Wozniak MA, Kittner SJ, Tuhrim S, Cole JW, Stern B, Dobbins M, et al. Frequency of unrecognized Fabry disease among young European-American and African-American men with first ischemic stroke. Stroke. 2010;41(1):78-81. https://doi.org/10.1161/STROKEAHA.109.558320 